\title{
Análise da cobertura dos planos de saúde médicos relacionados aos exames de detecção de COVID- 19 no Brasil
}

\author{
Analysis of coverage of medical health plans related to COVID-19 detection tests in Brazil \\ Análisis de la cobertura de los planes de salud relacionados con las pruebas de detección de \\ COVID-19 en Brasil
}

Recebido: 10/06/2021 | Revisado: 17/06/2021 | Aceito: 08/07/2021 | Publicado: 09/07/2021

Clea Adas Saliba Garbin

ORCID: https://orcid.org/0000-0001-5069-8812 Universidade Estadual Paulista, Brasil E-mail: clea.saliba-garbin@unesp.br

Julio Martinez Alves Oliveira

ORCID: https://orcid.org/0000-0002-3173-9444 Universidade Estadual Paulista, Brasil

E-mail: juliooliveira1994@hotmail.com

Tânia Adas Saliba

ORCID: https://orcid.org/0000 0003-1327-2913 Universidade Estadual Paulista, Brasil E-mail: tania.saliba@unesp.br

Gabriel Zopolatto Turci Dias

ORCID: https://orcid.org/0000 0003-2945-2943 Universidade Estadual Paulista, Brasil E-mail: gabrielzturci@hotmail.com

Artênio José Isper Garbin

ORCID: https://orcid.org/0000 0002-7017-8942 Universidade Estadual Paulista, Brasil E-mail: artenio.garbin@unesp.br

\begin{abstract}
Resumo
Com a declaração da pandemia do novo Coronavírus (COVID-19) pela Organização Mundial da Saúde (OMS), em 11 de março de 2020, a escalada por pesquisas sobre possíveis estratégias para o seu enfrentamento ganhou novo patamar. O objetivo neste estudo foi avaliar a cobertura das operadoras de planos de saúde em relação aos testes de COVID-19 determinada pela Agência Nacional de Saúde Suplementar (ANS) e analisar o número de exames de COVID-19 realizados no Brasil. Trata-se de um estudo documental, ecológico, que foi realizado do mês de março de 2020 à março de 2021. Verificou-se os dados divulgados pela ANS, com relação aos testes incluídos no Rol de Procedimentos e Eventos em Saúde. Já nas secretarias estaduais de saúde foram analisados o número de testes realizados diariamente no Brasil. Neste período foram implementados 07 testes pela ANS: o SARS-CoV-2 (CORONAVÍRUS COVID-19) - pesquisa por RT - PCR (com diretriz de utilização), o Dímero D (dosagem), o Procalcitonina (dosagem), os testes Pesquisa rápida para Influenza A e B ,e o PCR em tempo real para os vírus Influenza A e B além dos testes Pesquisa rápida para Vírus Sincicial Respiratório e o PCR em tempo real para Vírus Sincicial Respiratório. A região Sudeste realizou o maior número de testes no Brasil, com quase $50 \%$ do total, seguido pela região Nordeste, que testou aproximadamente $25 \%$ dos habitantes. Os tipos de testes determinados pela ANS estão de acordo com o recomendado pelo Ministério da Saúde do Brasil, entretanto, conclui-se que algumas operadoras de planos de saúde não estão seguindo a determinação da ANS em relação à cobertura destes exames influenciando negativamente no número de testes realizados no país.
\end{abstract}

Palavras-chave: Infecções por coronavirus; Saúde suplementar; Serviços de saúde.

\begin{abstract}
With the declaration of the new Coronavirus pandemic (COVID-19) by the World Health Organization (WHO), onMarch 11, 2020, the escalation by research on possible strategies for its confrontation has reached a new level. The objective of this study was to evaluate the coverage of health insurance companies in relation to COVID-19 tests determined by the National Supplementary Health Agency (ANS) and to analyze the number of COVID-19 tests performed in Brazil. This is a documentary, ecological study, which was carried out from March 2020 to March 2021. The data released by the National Supplementary Health Agency was verified in relation to the tests included in the List of Procedures and Events in Health of ANS. In the state health departments, the number of tests performed daily in Brazil was analyzed. During this period 07 tests were implemented by ANS: SARS-CoV-2 (CORONAVIRUS COVID-19) - RT search - PCR (with usage guidelines), D-Dimer (dosage), Procalcitonin (dosage), Research tests
\end{abstract}


rapid for Influenza A and B, and real-time PCR for Influenza A and B viruses in addition to the Quick Search tests for Respiratory Syncytial Virus and real-time PCR for Respiratory Syncytial Virus. The Southeast region carried out the largest number of tests in Brazil, with almost $50 \%$ of the total, followed by the Northeast region, which tested approximately $25 \%$ of the inhabitants. The types of tests determined by the ANS are in accordance with the recommendations of the Ministry of Health of Brazil, however, it is concluded that some health plan operators are not following the determination of the ANS in relation to the coverage of these tests, negatively influencing the number of tests carried out in the country.

Keywords: Coronavirus infections; Supplementary health; Health services.

\section{Resumen}

Con la declaración de la nueva pandemia de Coronavirus (COVID-19) por parte de la Organización Mundial de la Salud (OMS), el 11 de marzo de 2020, la escalada de investigaciones sobre posibles estrategias para su enfrentamiento ha alcanzado un nuevo nivel. El objetivo de este estudio fue evaluar la cobertura de las compañías de seguros de salud en relación a las pruebas COVID-19 determinadas por la Agencia Nacional de Salud Complementaria (ANS) y analizar el número de pruebas COVID-19 realizadas en Brasil. Se trata de un estudio documental, ecológico, que se realizó desde marzo de 2020 hasta marzo de 2021. Se verificaron los datos difundidos por la Agencia Nacional de Salud Complementaria en relación con las pruebas incluidas en la Lista de Procedimientos y Eventos en Salud de ANS. En los departamentos de salud estatales, se analizó el número de pruebas realizadas diariamente en Brasil. Durante este período, ANS implementó 07 pruebas: SARS-CoV-2 (CORONAVIRUS COVID19) - Búsqueda de RT - PCR (con pautas de uso), D-Dimer (dosis), Procalcitonina (dosis), Pruebas de investigación rápidas para influenza A y $\mathrm{B}$, y $\mathrm{PCR}$ en tiempo real para los virus de la influenza A y $\mathrm{B}$, además de las pruebas de búsqueda rápida para virus sincitial respiratorio y $\mathrm{PCR}$ en tiempo real para virus sincitial respiratorio. La región Sudeste realizó la mayor cantidad de pruebas en Brasil, con casi el 50\% del total, seguida de la región Nordeste, que evaluó aproximadamente al 25\% de los habitantes. Los tipos de pruebas determinadas por la ANS están de acuerdo con las recomendaciones del Ministerio de Salud de Brasil, sin embargo, se concluye que algunos operadores de planes de salud no están siguiendo la determinación de la ANS en relación a la cobertura de estas pruebas, negativamente influyendo en el número de pruebas realizadas en el país.

Palabras clave: Infecciones por coronavirus; Salud complementaria; Servicios de salud.

\section{Introdução}

Em dezembro de 2019, a cidade de Wuhan, localizada na província de Hubei, na China, vivenciou um surto de pneumonia de causa desconhecida (Heymann, Shindo \& World Health Organization, 2020). Em janeiro de 2020, pesquisadores chineses identificaram um novo coronavírus (SARS-CoV-2) como agente etiológico de uma síndrome respiratória aguda grave, denominada doença do coronavírus 2019, ou simplesmente COVID-19 (Kang, Choi, Kim \& Choi, 2020). A partir daí, a doença se espalhou pelo o mundo e chegou ao Brasil.

Como resultado destes acontecimentos, estão sendo discutidas no país a ação das operadoras de planos de saúde diante desta nova realidade. Os planos de saúde são seguros feitos com a finalidade de custear as despesas médicas quando necessárias. Cada operadora calcula seu plano conforme a metodologia publicada pela Agência Nacional de Saúde Suplementar (ANS) em dezembro de 2018, consistindo em um cálculo que combina o Índice de Valor das Despesas Assistenciais (IVDA) com o Índice de Preços ao Consumidor Amplo (IPCA). O IVDA é subdivido em três variáveis: a Variação das Despesas Assistenciais (VDA), o Fator de Ganhos de Eficiência (FGE) e a Variação da Receita por Faixa Etária (VFE) (Agência Nacional de Saúde Suplementar, 2021).

Com a chegada do novo coronavírus ao país, foi verificado que os planos de saúde não realizavam a cobertura dos testes de detecção da COVID-19, já que estes não eram previstos por lei. Porém, em 12 de março, a ANS incluiu o exame de detecção no Rol de Procedimentos obrigatórios aos contratantes de planos de saúde (Agência Nacional de Saúde Suplementar, 2020a). Em maio foram incluídos, também pela ANS, outros seis exames que auxiliam no diagnóstico do novo coronavírus (Agência Nacional de Saúde Suplementar, 2020b).

Os testes incluídos foram o SARS-CoV-2 (CORONAVÍRUS COVID-19) - pesquisa por RT - PCR (com diretriz de utilização), o Dímero D (dosagem), o Procalcitonina (dosagem), a Pesquisa rápida para Influenza A e B e PCR em tempo real para os vírus Influenza A e B e o Pesquisa rápida para Vírus Sincicial Respiratório e PCR em tempo real para Vírus Sincicial 
Respiratório. A partir de 29 de junho também foi adicionado à lista de coberturas obrigatórias dos planos de saúde o teste sorológico para a detecção (ANS: planos de saúde devem disponibilizar exames para detectar coronavírus, 2020).

A Organização Mundial da Saúde (OMS) recomendou que os países ampliem a realização de testes em pacientes com sintomas do novo coronavírus e fortaleçam ações de isolamento daqueles com suspeita de infecção. Na avaliação da entidade, que coordena os esforços globais de prevenção e combate à pandemia, tão ou mais importante que adotar medidas de redução da circulação e aglomeração de pessoas é assegurar os exames e o isolamento (Fundação Oswaldo Cruz, 2020).

O objetivo neste estudo foi avaliar a cobertura das operadoras de planos de saúde em relação aos testes de COVID-19 determinada pela ANS e analisar o número de exames de COVID-19 realizados no Brasil.

\section{Metodologia}

Trata-se de um estudo documental, de caráter quantitativo, ecológico, que foi realizado entre o mês de março de 2020 à março de 2021. Verificaram-se os dados divulgados pela ANS, com relação aos testes incluídos no Rol de Procedimentos e Eventos em Saúde. Já nas secretarias estaduais de saúde foram analisados o número de testes realizados diariamente no Brasil. Neste período foram implementados 07 testes pela ANS: o SARS-CoV-2 (CORONAVÍRUS COVID-19) - pesquisa por RT - PCR (com diretriz de utilização), o Dímero D (dosagem), o Procalcitonina (dosagem), os testes Pesquisa rápida para Influenza A e B , e o PCR em tempo real para os vírus Influenza A e B além dos testes Pesquisa rápida para Vírus Sincicial Respiratório e o PCR em tempo real para Vírus Sincicial Respiratório. Nos métodos quantitativos, faz- se a coleta de dados quantitativos ou numéricos por meio do uso de medições de grandezas e obtém -se por meio da metrologia, números com suas respectivas unidades. (Pereira et al., 2018)

Durante a pesquisa foram utilizados dados secundários disponíveis em sites oficiais do Ministério da Saúde do Brasil, sem identificação de sujeitos, sendo dispensada de apreciação em comitê de ética em pesquisa, em conformidade com a Resolução 466/2012 do Conselho Nacional de Saúde.

\section{Resultados}

A ANS determinou a adoção de 7 exames que auxiliam no diagnóstico e tratamento do novo Coronavírus na lista de coberturas obrigatórias dos planos de saúde. A Tabela 1 indica os exames e as datas em que os testes foram incluídos pela ANS no rol de Procedimentos e Eventos em Saúde da ANS no período de março à agosto de 2020.

Tabela 1 - Nome do exame e data de inclusão do teste no rol de procedimentos e eventos em saúde da ANS. Brasil, 2021.

\begin{tabular}{l|l}
\hline Exame & Data de inclusão \\
\hline $\begin{array}{l}\text { SARS-CoV-2 (CORONAVÍRUS COVID-19) - pesquisa por } \\
\text { RT - PCR }\end{array}$ & 12 de março de 2020 \\
\hline Dímero D (dosagem) & 27 de maio de 2020 \\
\hline Procalcitonina (dosagem) & 27 de maio de 2020 \\
\hline Pesquisa rápida para Influenza A e B & 27 de maio de 2020 \\
\hline PCR em tempo real para os vírus Influenza A e B & 27 de maio de 2020 \\
\hline Pesquisa rápida para Vírus Sincicial Respiratório & 27 de maio de 2020 \\
\hline PCR em tempo real para Vírus Sincicial Respiratório & 27 de maio de 2020 \\
\hline
\end{tabular}


Na Tabela 1, é possível analisar todos os testes que foram incluídos como testes de cobertura obrigatória pelas agências de planos de saúde no Brasil. A realização destes testes é importante para encontrar a presença do vírus causador da COVID-19, auxiliando no tratamento da doença.

A Tabela 2 apresenta os dados dos testes realizados e casos confirmados nos estados da região Sudeste do Brasil, atualizados de acordo com os números divulgados por cada secretaria estadual de Saúde (Stephanou, 2021).

Tabela 2 - Testes realizados e casos confirmados na região Sudeste. Brasil,2021.

\begin{tabular}{l|l|l|l|l}
\hline Estado & População & $\begin{array}{l}\text { Testes } \\
\text { Realizados }\end{array}$ & $\begin{array}{l}\text { Casos } \\
\text { Confirmados }\end{array}$ & Última Atualização \\
\hline São Paulo & 46.289 .333 & 9.544 .530 & 2.164 .066 & $28 / 02 / 2021$ \\
\hline Rio de Janeiro & 17.366 .189 & 2.313 .502 & 601.666 & $26 / 01 / 2021$ \\
\hline Minas Gerais & 21.292 .666 & 3.316 .118 & 956.468 & $28 / 02 / 2021$ \\
\hline Espírito Santo & 4.064 .052 & 1.017 .962 & 340.936 & $11 / 03 / 2021$ \\
\hline Total & 89.012 .240 & 16.192 .112 & 4.063 .136 & \\
\hline
\end{tabular}

Fonte: Stephanou (2021).

A região Sudeste do Brasil possui o maior percentual populacional do país. É também o local onde foram notificados o maior número de casos confirmados de COVID-19, e o maior número de testes realizados da doença no Brasil.

Tabela 3 - Testes realizados e casos confirmados na região Sul. Brasil, 2021.

\begin{tabular}{l|l|l|l|l}
\hline Estado & População & $\begin{array}{l}\text { Testes } \\
\text { Realizados }\end{array}$ & $\begin{array}{l}\text { Casos } \\
\text { Confirmados }\end{array}$ & $\begin{array}{l}\text { Uttima } \\
\text { Atualização }\end{array}$ \\
\hline Paraná & 11.516 .840 & 2.503 .057 & 745.898 & $11 / 03 / 2021$ \\
\hline Santa Catarina & 7.252 .502 & 1.683 .529 & 717.454 & $03 / 03 / 2021$ \\
\hline Rio Grande do Sul & 11.422 .973 & 2.855 .545 & 720.461 & $11 / 03 / 2021$ \\
\hline Total & 30.192 .315 & 7.042 .131 & 2.183 .813 & \\
\hline
\end{tabular}

Fonte: Stephanou (2021).

Na Tabela 3, estão indicados os números de testes realizado e os casos confirmados na região Sul do Brasil, compreendendo os estados do Paraná, Santa Catarina e Rio Grande do Sul (Stephanou, 2021). 
Research, Society and Development, v. 10, n. 8, e55510817041, 2021

(CC BY 4.0) | ISSN 2525-3409 | DOI: http://dx.doi.org/10.33448/rsd-v10i8.17041

Tabela 4 - Testes realizados e casos confirmados na região Centro Oeste. Brasil, 2021.

\begin{tabular}{l|l|l|l|l}
\hline Estado & População & $\begin{array}{l}\text { Testes } \\
\text { Realizados }\end{array}$ & $\begin{array}{l}\text { Casos } \\
\text { Confirmados }\end{array}$ & $\begin{array}{l}\text { Última } \\
\text { Atualização }\end{array}$ \\
\hline Mato Grosso & 3.526 .220 & 958.352 & 269.155 & $11 / 03 / 2021$ \\
\hline Mato Grosso do Sul & 2.809 .394 & 620.149 & 192.430 & $12 / 03 / 2021$ \\
\hline Distrito Federal & 3.055 .149 & 782.118 & 312.956 & $26 / 01 / 2021$ \\
\hline Goiás & 7.113 .540 & 879.197 & 430.174 & $12 / 03 / 2021$ \\
\hline Total & 16.504 .303 & 3.239 .816 & 1.204 .715 & \\
\hline
\end{tabular}

Fonte: Stephanou (2021).

Na Tabela 4, estão indicados os números de casos confirmados e testes realizados nos estados da região Centro Oeste. O estado de Goiás possui o maior número de habitantes da região, mas foi no estado de Mato Grosso que foram realizados o maior número de testes neste período (Stephanou, 2021).

Tabela 5 - Testes realizados e casos confirmados na região Nordeste. Brasil, 2021.

\begin{tabular}{l|l|l|l|l}
\hline Estado & População & $\begin{array}{l}\text { Testes } \\
\text { Realizados }\end{array}$ & $\begin{array}{l}\text { Casos } \\
\text { Confirmados }\end{array}$ & Última Atualização \\
\hline Alagoas & 3.351 .543 & 339.887 & 138.065 & $11 / 03 / 2021$ \\
\hline Bahia & 14.930 .634 & 1.978 .117 & 730.542 & $09 / 01 / 2021$ \\
\hline Ceará & 9.187 .103 & 1.499 .827 & 459.782 & $11 / 03 / 2021$ \\
\hline Maranhão & 7.114 .598 & 548.162 & 226.172 & $08 / 03 / 2021$ \\
\hline Paraíba & 4.039 .277 & 675.612 & 234.254 & $09 / 03 / 2021$ \\
\hline Pernambuco & 9.616 .621 & 1.284 .054 & 314.793 & $10 / 03 / 2021$ \\
\hline Piauí & 3.281 .480 & 562.230 & 182.650 & $11 / 03 / 2021$ \\
\hline Rio Grande do Norte & 3.532 .165 & 635.939 & 178.582 & $10 / 03 / 2021$ \\
\hline Sergipe & 2.318 .822 & 329.561 & 157.340 & $09 / 03 / 2021$ \\
\hline Total & 57.372 .243 & 7.853 .389 & 2.622 .180 & \\
\hline
\end{tabular}

Fonte: Stephanou (2021).

A Tabela 5 demonstra os números de casos confirmados e testes realizados na região nordeste, que representa a região com o maior número de estados do país. A Bahia é o estado que apresentou o maior número de testes realizados e casos confirmados da doença (Stephanou, 2021). 
Research, Society and Development, v. 10, n. 8, e55510817041, 2021

(CC BY 4.0) | ISSN 2525-3409 | DOI: http://dx.doi.org/10.33448/rsd-v10i8.17041

Tabela 6 - Testes realizados e casos confirmados na região Norte. Brasil, 2021.

\begin{tabular}{l|l|l|l|l}
\hline Estado & População & $\begin{array}{l}\text { Testes } \\
\text { Realizados }\end{array}$ & $\begin{array}{l}\text { Casos } \\
\text { Confirmados }\end{array}$ & Última Atualização \\
\hline Amazonas & 4.207 .714 & 806.449 & 328.763 & $10 / 03 / 2021$ \\
\hline Acre & 894.470 & 165.878 & 61.394 & $11 / 03 / 2021$ \\
\hline Amapá & 861.773 & 149.895 & 87.095 & $11 / 03 / 2021$ \\
\hline Pará & 8.690 .745 & 980.727 & 380.924 & $30 / 11 / 2020$ \\
\hline Rondônia & 1.796 .460 & 431.533 & 162.818 & $08 / 03 / 2021$ \\
\hline Roraima & 631.181 & 191.334 & 84.909 & $12 / 03 / 2021$ \\
\hline Tocantins & 1.590 .248 & 385.111 & 123.537 & $12 / 03 / 2021$ \\
\hline Total & 18.672 .591 & 3.110 .927 & 1.229 .440 & \\
\hline
\end{tabular}

Fonte: Stephanou (2021).

A Tabela 6 indica o número de casos confirmados e testes realizados na região norte do país. O estado do Pará representa o estado com o maior número de habitantes e de testes realizados na região norte (Stephanou, 2021).

Tabela 7 - Número de testes realizados por região. Brasil,2021.

\begin{tabular}{l|l|l}
\hline Regiões & Testes realizados & $\%$ \\
\hline Sudeste & 16.192 .112 & $43,25 \%$ \\
\hline Nordeste & 7.853 .389 & $21,00 \%$ \\
\hline Norte & 3.110 .927 & $8,30 \%$ \\
\hline Centro-Oeste & 3.239 .816 & $8,65 \%$ \\
\hline Sul & 7.042 .131 & $18,80 \%$ \\
\hline Total & 37.438 .375 & $100 \%$ \\
\hline
\end{tabular}

Fonte: Stephanou (2021).

A tTabela 7 indica o número de testes realizados no Brasil por região até o mês de março de 2021. A região Sudeste concentra o maior número de exames realizados, com aproximadamente $43 \%$ dos testes identificados no país até o momento (Stephanou, 2021).

\section{Discussão}

A transmissão do coronavírus pode ocorrer por gotículas de saliva, espirro, tosse ou catarro, que podem ser repassados por toque ou aperto de mão, objetos ou superfícies contaminadas pelo infectado (Huang et al., 2020; Li et al., 2020) e o diagnóstico precoce de novos casos de COVID-19 através de testagem é crucial para interromper a disseminação do vírus (Reusken et al., 2020) por meio de estratégias de isolamento social e quarentena.

Em diversos países, uma das medidas mais efetivas em termos de detecção e prevenção de novos casos de COVID-19 foi a testagem em ampla escala da população (Beeching, Fletcher \& Beadsworth, 2020; Ng, et al., 2020; Peto, 2020) já recomendada pela OMS assim como a indicação do regime de quarentena por 14 dias para os casos identificados, e seus contatos diretos após o início dos sintomas (Brasil, 2020b ; World Health Organization, 2020). 
Alguns países da Ásia e da Oceania apresentaram controle da pandemia com a combinação de estratégias com a ampla testagem. Na China, por exemplo, algumas medidas foram importantes para o controle da COVID-19, como a detecção precoce de casos através de testagem, isolamento dos casos e rastreio de todos os contactantes, e atendimento clínico de qualidade para os infectados (Rong, Yang, Chu \& Fan, 2020).

No Brasil, a determinação da ANS de obrigar as operadoras de planos de saúde de incluírem estes exames (tabela 1) são extremamente válidos, já que tratam-se de importantes ferramentas para encontrar a presença do vírus causador da COVID-19, trazendo benefícios para o tratamento da doença, que já causou milhões de mortes ao redor do mundo.

Até maio de 2020, os testes para diagnóstico de COVID-19 eram concentrados em 5 laboratórios particulares no Brasil. Na época, cerca de 870 mil testes haviam sido realizados, sendo 47,2\% deles feitos em clínicas particulares e o restante dos testes realizados pelo Sistema Único de Saúde (SUS) (Forato, 2020). Já no dia primeiro de julho de 2020, o Ministério da Saúde informou ter aumentado a testagem de RT-PCR na Rede Nacional de Laboratórios de Saúde Pública em 869\% desde o início da pandemia (Brasil, 2020a).

O teste SARS-CoV-2 (CORONAVÍRUS COVID-19) - pesquisa por RT - PCR foi indicado para cobrir beneficiários de planos de saúde com segmentação ambulatorial, hospitalar ou referência está sendo indicado nos casos em que há indicação médica, de acordo com o protocolo e as diretrizes definidas pelo Ministério da Saúde (Agência Nacional de Saúde Suplementar, 2020a).

O Dímero D (dosagem) já era de cobertura obrigatória pelos planos de saúde, porém, ainda não era utilizado para casos relacionados à COVID-19. É um exame fundamental para diagnóstico e acompanhamento do quadro trombótico e tem papel importante na avaliação prognóstica na evolução dos pacientes com COVID-19 (Agência Nacional de Saúde Suplementar, 2020b). O procedimento Procalcitonina (dosagem) é recomendado entre as investigações clínico-laboratoriais em pacientes graves de COVID-19, auxiliando na distinção entre situações de maior severidade e quadros mais brandos da doença (Agência Nacional de Saúde Suplementar, 2020b).

Já os testes de pesquisa rápida para Influenza A e B e PCR em tempo real para os vírus Influenza A e B são indicados para diagnóstico da Influenza. A proposta consiste na incorporação dos dois procedimentos para minimizar questões de disponibilidade e para otimizar o arsenal diagnóstico disponível. A pesquisa rápida é recomendada para investigações clínicolaboratoriais em pacientes graves. O diagnóstico diferencial é importante, pois a influenza também pode ser causa de Síndrome Respiratória Aguda Grave (SARS) (Agência Nacional de Saúde Suplementar, 2020b).

O teste chamado Pesquisa rápida para Vírus Sincicial Respiratório e o teste PCR em tempo real para o mesmo Vírus Sincicial Respiratório são testes indicados para diagnóstico da infeção pelo Vírus Sincicial Respiratório (VSR). A proposta consiste na incorporação dos dois procedimentos para minimizar questões de disponibilidade e para aprimorar as possibilidades. O teste rápido para o VSR é útil no diagnóstico diferencial de COVID-19 em crianças com infecção viral grave respiratória (Agência Nacional de Saúde Suplementar, 2020b).

Até o mês de março de 2021, dos mais de 37 milhões de testes realizados por todo o Brasil, foram confirmados mais de 11 milhões de casos de pacientes infectados pelo novo coronavírus. A região sudeste foi a que teve o maior número de testes realizados, com cerca de $43 \%$ do total. A região nordeste aparece em seguida com o total de $21 \%$ dos exames realizados no país. A região Sul representa 18,8\%. O Centro Oeste responde por 8,6\% dos testes, seguida por Norte com 8,3\%.

Em relação ao número de casos confirmados, o Sudeste teve o maior número de positivados para a doença com quase metade dos casos. A região nordeste aparece em segundo lugar, seguido pelas regiões Sul, Centro Oeste e Norte. Embora a região sudeste tenha concentrado o maior número absoluto de casos confirmados, a região Norte do país apresentou a maior taxa de incidência da doença até a SE 20 (semana epidemiológica 20). Nesta região, houve registros de diversos empecilhos de 
adesão, por parte da população, para o isolamento social recomendado pelas autoridades de saúde (Universidade do Estado do Rio de Janeiro, 2020).

Diversas operadoras estão se recusando a cumprir com a determinação da ANS em realizar a cobertura dos testes para a doença. Muitos pacientes estão encontrando problemas nos hospitais para realizar o exame. O caminho para aqueles que possuem planos de saúde e venham a passar por este problema é realizar reclamação na própria ANS, que poderá multar as empresas que perpetuam esta prática (Guaracho, 2020).

A ANS orienta que o beneficiário não se dirija a hospitais ou outras unidades de saúde sem antes consultar sua operadora de plano de saúde, para informações sobre o local mais adequado para a realização de exame ou para esclarecimento de dúvidas sobre diagnóstico ou tratamento da doença (ANS, 2020).

Ressalta-se a importância das estratégias de testagem (Peto, 2020) associadas à organização do sistema de saúde no enfrentamento à pandemia, pois o número de casos confirmados permite o monitoramento da progressão da doença (Hasell, Ortiz-Ospina, Mathieu, Ritchie, Beltekian \& Roser, 2020) o que pode evitar o colapso da rede de atenção hospitalar, a partir da articulação entre distintos níveis de atenção à saúde.

O processo de investigação, notificação e monitoramento de casos de COVID-19 pelo Sistema Nacional de Vigilância em Saúde do SUS, é fundamental na resposta ao COVID-19, pois possui atuação em todo o território brasileiro de modo articulado e hierarquizado, por meio dos Centros de Informações Estratégicas e Respostas em Vigilância em Saúde (CIEVS), das secretariais municipais e estaduais de saúde (Teixeira, Costa, Carmo, Oliveira \& Penna, 2018).

Além das atividades rotineiras, o SNVS é acionado na ocorrência de situações de Emergências em Saúde Pública de Importância Nacional, como o caso da pandemia de COVID-19 (Brasil, 2020c). Nestes casos, a rede de serviços deve se organizar para dar respostas rápidas com o emprego urgente de medidas de prevenção, controle e contenção de riscos, danos e agravos à saúde pública (Brasil, 2020b).

\section{Conclusão}

Os tipos de testes determinados pela ANS estão de acordo com o recomendado pelo Ministério da Saúde do Brasil, entretanto, conclui-se que algumas operadoras de planos de saúde não estão seguindo a determinação da ANS em relação a cobertura destes exames, e assim, influenciando negativamente no número de testes realizados no país. Neste trabalho, foram consultados dados secundários, o que restringe análises mais aprofundadas. Embora o estudo apresente esta limitação, ele traz à tona dados importantes para discussão sobre a cobertura das operadoras de planos de saúde em relação aos exames que detectam a COVID19.Estudos revelam a importância de se realizar o maior número de testes possíveis em uma população, para que assim, os indivíduos positivados para a doença sejam isolados de forma rápida, diminuindo a contaminação. Os profissionais, e as autoridades de saúde, devem adotar estratégias e planos de ação que busquem testar o maior número possível de habitantes do país, contribuindo assim para controlar o avanço da COVID19 nos estados e municípios. Novas pesquisas podem ser realizadas por meio de aplicação de questionários e inquéritos entre os usuários da saúde suplementar no Brasil.

\section{Agradecimentos}

O presente trabalho foi realizado com apoio da Coordenação de Aperfeiçoamento de Pessoal de Nível Superior - Brasil (CAPES) - Código de Financiamento 001. 


\section{Referências}

Agência Nacional de Saúde Suplementar (2021). Metodologia de cálculo. http://www.ans.gov.br/planos-de-saude-e-operadoras/espaco-doconsumidor/reajustevariacao-de-mensalidade/reajuste-anual-de-planos-individuais-familiares/metodologia-de-calculo

Agência Nacional de Saúde Suplementar (2020a). ANS inclui exame para detecção de Coronavírus no rol de procedimentos obrigatórios. http://www.ans.gov.br/aans/noticias-ans/consumidor/5405-ans-inclui-exame-para-deteccao-de-coronavirus-no-rol-de-procedimentosobrigatorios

Agência Nacional de Saúde Suplementar (2020b). ANS inclui mais seis exames no rol para auxiliar no diagnóstico e tratamento do novo Coronavírus. http://www.ans.gov.br/aans/noticias-ans/coronavirus-covid-19/coronavirus-todas-as-noticias/5546-ans-inclui-mais-seis-exames-norol-de-coberturasobrigatorias-para-auxiliar-na-deteccao-do-novo-coronavirus

ANS: planos de saúde devem disponibilizar exames para detectar coronavírus (2020). https://www.migalhas.com.br/quentes/321653/ans--planosde-saudedevem-disponibilizar-exames-para-detectar-coronavirus

Beeching, N. J., Fletcher, T. E., \& Beadsworth, M. (2020). Covid-19: testing times. BMJ, 369, m1403.

Brasil. Ministério da Saúde (2020a) Laboratórios públicos ampliam em $869 \%$ capacidade de testagem para Covid-19 no Brasil. https://antigo.saude.gov.br/noticias/agencia-saude/47151-laboratorios-publicos-ampliam-em-869-capacidade-de-testagem-para-covid-19-nobrasil

Brasil. Ministério da Saúde (2020b). Centro de informações estratégicas em vigilância em saúde - CIEVS http://bvsms.saude.gov.br/bvs/publicacoes/centro_informacoes_estrategicas_vigilancia_saude.pdf

Brasil. Ministério da Saúde (2020c). Emergência de saúde pública de importância nacional pela doença pelo Coronavírus 2019: vigilância integrada de síndromes respiratórias agudas doença pelo Coronavírus 2019, influenza e outros vírus respiratórios.

Forato, F. (2020). COVID-19 no BR: quase metade dos testes foram feitos em 5 laboratórios privados. https://canaltech.com.br/saude/covid-19no-br-quasemetade-dos-testes-foram-feitos-em-5-laboratorios-privados-165637/

Fundação Oswaldo Cruz (2020). Organização Mundial da Saúde quer testes e isolamento de casos suspeitos para conter Covid-19. https://www.canalsaude.fiocruz.br/noticias/noticiaAberta/organizacao-mundial-da-saude-quer-testes-e-isolamento-de-casos-suspeitos-paraconter-covid1916032020\#: :text=A\%20Organiza\%C3\%A7\%C3\%A3o\%20Mundial\%20da\%20Sa\%C3\%BAde,daqueles\%20com\%20suspeita\%20de\%20infe c\% $3 \% \mathrm{~A} 7 \% \mathrm{C} 3 \% \mathrm{~A} 3 \mathrm{O}$

Guaracho, R. F. (2020). Planos de saúde não podem recusar cobertura dos testes do coronavírus. https://www.jornaldocomercio.com/_conteudo/e speciais/ orn al_da_lei /2020/03/731909-planos-de-saude-nao-podem-recusar-cobertura-dostestes-do-coronavirus.html

Hasell, J., Ortiz-Ospina, E., Mathieu, E., Ritchie, H., Beltekian, D.M.B., \& Roser, M. (2020). To understand the global pandemic, we need globas testing - the Our World in Data COVID-19 Testing dataset. University of Oxford.

Heymann, D. L., Shindo, N., \& WHO Scientific and Technical Advisory Group for Infectious Hazards (2020). COVID-19: what is next for public health? Lancet, 395(10224), 542-545.

Huang, L., Zhang, X., Zhang, X., Wei, Z., Zhang, L., Xu, J., Liang, P., Xu, Y., Zhang, C., \& Xu, A. (2020). Rapid asymptomatic transmission of COVID-19 during the incubation period demonstrating strong infectivity in a cluster of youngsters aged 16-23 years outside Wuhan and characteristics of young patients with COVID-19: a prospective contact-tracing study. The Journal of Infection, 80(6), e1-e13.

Kang, D., Choi, H., Kim, J. H., \& Choi, J. (2020). Spatial epidemic dynamics of the COVID-19 outbreak in China. International Journal of Infectious Diseases, 94, 96-102.

Li, Q., Guan, X., Wu, P., Wang, X., Zhou, L., Tong, Y., Ren, R., Leung, K., Lau, E., Wong, J. Y., Xing, X., Xiang, N., Wu, Y., Li, C., Chen, Q., Li, D., Liu, T., Zhao, J., Liu, M., Tu, W., Chen, C., Jin, L., Yang, R., Wang, Q., Zhou, S., Wang, R., Liu, H., Luo, Y., Liu, Y., Shao, G., Li, H., Tao, Z., Yang, Y., Deng, Z., Liu, B., Ma, Z., Zhang, Y., Shi, G., Lam, T.T.Y., Wu, J.T., Gao, G.F., Cowling, B.J., Yang, B., Leung, G.M., \& Feng, Z. (2020).

Early transmission dynamics in Wuhan, China, of novel coronavirus-infected pneumonia. The New England Journal of Medicine, $382(13)$, $1199-1207$.

Ng, Y., Li, Z., Chua, Y. X., Liang, W., Zhao, Z., Er, B., Pung, R., Chiew, C. J., Lye, D. C., Heng, D., \& Lee, V J . (2020). Evaluation of the effectiveness of surveillance and containment measures for the first 100 patients with COVID-19 in Singapore - january 2-february 29, 2020. Morbidity and Mortality Weekly Report, 69(11), 307-311.

Pereira, A. S. et al. (2018). Metodologia da pesquisa científica. UFSM. https://repositorio.ufsm.br/bitstream/handle/1/15824/Lic_Computacao_MetodologiaPesquisa-Cientifica.pdf?sequence $=1$.

Peto, J. (2020). Covid-19 mass testing facilities could end the epidemic rapidly. BMJ, 368, m1163.

Reusken, C., Broberg, E. K., Haagmans, B., Meijer, A., Corman, V. M., Papa, A., Charrel, R., Drosten, C., Koopmans, M., Leitmeyer, K., \& On Behalf Of Evd-LabNet And Erli-Net (2020). Laboratory readiness and response for novel coronavirus (2019-nCoV) in expert laboratories in 30 EU/EEA countries, January 2020. Euro Surveillance, 25(6), 2000082. 
Research, Society and Development, v. 10, n. 8, e55510817041, 2021

(CC BY 4.0) | ISSN 2525-3409 | DOI: http://dx.doi.org/10.33448/rsd-v10i8.17041

Rong, X. M., Yang, L., Chu, H. D., \& Fan, M. (2020). Effect of delay in diagnosis on transmission of COVID-19. Mathematical Biosciences and Engineering, 17(3), 2725-2740.

Stephanou, G. (2021). Painel COVID-19: estatísticas do coronavírus em tempo real. Disponível em http://www.giscard.com.br/coronavirus/indicetestesrealizados-covid19-brasil.php

Teixeira, M. G., Costa, M. C. N., Carmo, E. H., Oliveira, W. K., \& Penna, G. O. (2018). Health surveillance at the SUS: Development, effects and perspectives. Ciência \& Saúde Coletiva, 23(6), 1811-1818.

Universidade do Estado do Rio de Janeiro (2020). Estudo mostra eficiência do isolamento social contra o novo coronavírus. https://www.uerj.br/noticia/11078/

World Health Organization (2020). Rolling updates on coronavirus disease (COVID-19). https://www.who.int/emergencies/diseases/novelcoronavirus2019/events-as-they-happen 